\title{
Picroside II attenuates fatty acid accumulation in HepG2 cells via modulation of fatty acid uptake and synthesis
}

\author{
Hiteshi Dhami-Shah ${ }^{1,2,3}$, Rama Vaidya', Shobha Udipi ${ }^{1,3}$, Srividhya Raghavan², Shiny Abhijit ${ }^{2}$, Viswanathan Mohan $^{2}$, \\ Muthuswamy Balasubramanyam², and Ashok Vaidya' \\ 'Division of Endocrine and Metabolic Disorders, Kasturba Health Society, Medical Research Centre, Mumbai; ${ }^{2}$ Department of Cell and \\ Molecular Biology, Madras Diabetes Research Foundation, Chennai; ${ }^{3}$ Department of Food Science and Nutrition, Shreemati Nathibai \\ Damodar Thackersey Women's University, Mumbai, India
}

Background/Aims: Hepatic steatosis is caused by an imbalance between free fatty acids (FFAs) uptake, utilization, storage, and disposal. Understanding the molecular mechanisms involved in FFAs accumulation and its modulation could drive the development of potential therapies for Nonalcoholic fatty liver disease. The aim of the current study was to explore the effects of picroside II, a phytoactive found in Picrorhiza kurroa, on fatty acid accumulation vis-à-vis silibinin, a known hepatoprotective phytoactive from Silybum marianum.

Methods: HepG2 cells were loaded with FFAs (oleic acid:palmitic acid/2:1) for 20 hours to mimic hepatic steatosis. The FFAs concentration achieving maximum fat accumulation and minimal cytotoxicity $(500 \mu \mathrm{M})$ was standardized. HepG2 cells were exposed to the standardized FFAs concentration with and without picroside II pretreatment.

Results: Picroside II pretreatment inhibited FFAs-induced lipid accumulation by attenuating the expression of fatty acid transport protein 5, sterol regulatory element binding protein 1 and stearoyl CoA desaturase. Preatreatment with picroside II was also found to decrease the expression of forkhead box protein 01 and phosphoenolpyruvate carboxykinase.

Conclusions: These findings suggest that picroside II effectively attenuated fatty acid accumulation by decreasing FFAs uptake and lipogenesis. Picroside II also decreased the expression of gluconeogenic genes. (Clin Mol Hepatol 2018;24:77-87)

Keywords: Nonalcoholic fatty liver disease; Picrorhiza kurroa; Picroside Il; Reverse pharmacology; Silibinin

\section{INTRODUCTION}

Nonalcoholic fatty liver disease (NAFLD) is a major degenerative liver disorder caused by accumulation of excessive fat in hepatocytes, and has detrimental effect on hepatic fatty acid metabo- lism. ${ }^{1}$ NAFLD covers a spectrum of clinical conditions beginning with simple steatosis to steatohepatitis, degenerative fibrosis and irreversible cirrhosis. ${ }^{2}$ It is estimated that $6.3-33 \%$ of the world's population, including children, is affected with NAFLD. ${ }^{3}$ Hence it is imperative to prevent development of NAFLD at an early stage

\footnotetext{
Abbreviations:

CDNAs, complementary DNAs; CPT1, carnitine palmitoyltransferase 1; FATP5, fatty acid transporter protein 5; FFAs, free fatty acids; FOXO1, forkhead box protein O1; NAFLD, nonalcoholic fatty liver disease; ORO, oil red O; PEPCK, phosphoenolpyruvate carboxykinase; P. kurroa, Picrorhiza kurroa; PPARa, peroxisome proliferator activated receptor a; RP, reverse pharmacology; SCD, stearoyl CoA desaturase; SREBP-1, sterol regulatory element binding protein-1; TG, triglyceride; T2D, type 2 diabetes; VLDL, very low density lipoprotein
}

\section{Corresponding author : Hiteshi Dhami-Shah}

Division of Endocrine and Metabolic Disorders, Kasturba Health Society, Medical Research Centre, K D Road, Vile Parle West, Mumbai 400056, India Tel: +91-22-26715157

E-mail: hiteshi.dhami@gmail.com

http://orcid.org/0000-0002-6092-3873 
or regress it, such that an aggressive inflammatory condition like steatoheaptitis is avoided.

Despite its wide prevalence, there is limited understanding on the precise molecular mechanisms responsible for the development and progression of hepatic steatosis. ${ }^{4}$ In a healthy individual, free fatty acids (FFAs) derived from either chylomicrons and/or adipose tissue (lipolysis) are taken up by hepatocytes. These FFAs are metabolized via $\beta$-oxidation or are esterified to triglycerides (TG) which are either stored as lipid droplets or secreted as very low density lipoprotein (VLDL). ${ }^{5}$ Hepatic steatosis ensues when there is an increase in FFAs uptake, lipogenesis, and storage of lipids with a concomitant decrease in VLDL-TG secretion. ${ }^{4}$

Apart from life style modifications, current pharmacological therapies used for NAFLD have not proved to be very effective. ${ }^{6}$ Ayurveda, the oldest system of traditional medicine in India, has a rich heritage of several medicinal plants and their formulations which are used for the treatment of liver disorders. Picrorhiza kurroa (P. kurroa) is a distinguished medicinal plant whose roots and rhizomes have shown beneficial effect in ameliorating obesity, jaundice, malaria, and asthma. ${ }^{7}$ The hydrocholeretic activity of $P$. kurroa was first investigated in dogs with biliary fistula. ${ }^{8}$ Later, its therapeutic activity was studied by our group in a double-blind, placebo-controlled trial in patients with viral hepatitis using Arogyawardhini. ${ }^{9}$ Arogyawardhini, a formulation containing $50 \%$ P. kurroa, when administered for 14 days (750 mg thrice a day), significantly reduced all symptoms; hepatomegaly, serum bilirubin and glutamic-pyruvic transaminase levels. ${ }^{9}$ The plant extract also provided protection against carbon tetrachloride, paracetamol, thioacetamide and galactosamine-induced fat deposition and liver damage in rats. ${ }^{10-13}$

Since $P$. kurroa extract was found to be an effective hepatoprotective herb, it would be valuable to determine its active constituents for their novel therapeutic application. The active elements present in P. kurroa are the iridoid glycosides; picroside I, II and III. With the emerging challenge of NAFLD, the current study was aimed at exploring the effect of phytoactives, present in $P$. kurroa, picroside I and II on hepatic fatty acid accumulation vis-à-vis silibinin, a known hepatoprotective phytoactive from Silybum marianum. ${ }^{14}$

\section{MATERIALS AND METHODS}

\section{Cell culture}

HepG2 cells (AddrexBio, San Diego, CA, USA) were cultured as monolayers in DMEM (Gibco, Life Technologies, Waltham, MA, USA) with 10\% fetal bovine serum (Invitrogen, Waltham, MA, USA) and $1 \%$ of antibiotic-antimycotic solution (Gibco, Life Technologies, Waltham, MA, USA). Cells were maintained in a humidified incubator in $5 \% \mathrm{CO}_{2}$ at $37{ }^{\circ} \mathrm{C}$ (Thermo Scientific, Waltham, MA, USA). All the experiments were performed when the cells reached $\sim 75-80 \%$ confluence in $5 \%$ DMEM. The experiments were repeated individually for four to six times to confirm the reproducibility.

\section{Bovine serum albumin-FFAs conjugate}

Prior to overloading the cells with long chain FFAs, palmitic acid (Sigma-Aldrich, St. Louis, MO, USA) and oleic acid (Sigma-Aldrich, St. Louis, MO, USA) were conjugated individually with BSA (Sisco Research Laboratories Pvt Ltd, Mumbai, India). BSA favors transportation of FFAs inside the cells. FFAs-BSA conjugate was prepared as previously described with minor modifications in the protocol. ${ }^{15}$ Briefly, $100 \mathrm{mM}$ of FFAs stock was prepared in $0.1 \mathrm{M}$ $\mathrm{NaOH}$ by heating at $70^{\circ} \mathrm{C}$ in a thermo mixer (Eppendorf, Hauppauge, NY, USA) for an hour. Simultaneously, 5\% (wt/vol) BSA was dissolved in double distilled water. On complete dilution of FFAs stock in $\mathrm{NaOH}$, the conjugate was prepared in an adjacent water bath at $55^{\circ} \mathrm{C}$. FFAs-BSA conjugate stock of $10 \mathrm{mM}$ was prepared and filtered using $0.45 \mu \mathrm{m}$ pore size polyvinylidene fluoride hydrophilic membrane filter. The conjugate was later cooled to room temperature and stored at $-20^{\circ} \mathrm{C}$. At this temperature the conjugate was found to be stable for 3-4 weeks. Since the FFAs were conjugated with $5 \%$ BSA, the control cells were also treated with $5 \% \mathrm{BSA}$.

\section{Cell cytotoxicity detection}

HepG2 cells $\left(7 \times 10^{3}\right.$ cells/well) seeded in 96 -well plates were treated with different concentrations of FFAs mixture of oleic and palmitic acid in the ratio of 2:1 (250 to 1,000 $\mu \mathrm{M})$, picroside I and II (3 to $300 \mu \mathrm{M}$ ) (Natural Remedies Pvt Ltd, Bengaluru, Karnataka, India) and silibinin (3 to $300 \mu$ M) (Sigma-Aldrich, St. Louis, MO, USA) for 24 hours. Post treatment, the cells were incubated with 5 $\mathrm{mg} / \mathrm{mL}$ of methyl thiazolyl tetrazolium (Sigma-Aldrich, St. Louis, MO, USA) for 4 hours. The blue colored formazan crystals formed were dissolved in dimethyl sulfoxide and absorbance was measured at $570 \mathrm{~nm}$ (Bio rad 680 Elisa Reader). 


\section{Colorimetric determination of lipid content with Oil Red 0 staining}

HepG2 cells $\left(7 \times 10^{3}\right.$ cells/well) were incubated with FFAs mixture in 96-well plates for 20 hours. After treatment, the cells were fixed (4\% formaldehyde) and stained with Oil Red 0 (ORO) solution (3 mg/mL in 60\% isopropanol) for 5 minutes. ORO stain (Sigma-Aldrich, St. Louis, MO, USA) is primarily used to detect and quantify intracellular lipids. The lipid accumulated within the cells was quantified by disrupting the cells with 100\% isopropanol. The absorbance of the extracted solution was measured at 490 nm (Enspire - Multimode Plate Reader - PerkinElmer, Waltham, MA, USA). Once the FFAs model was standardized, inhibitory activity of the phytoactives was also examined with ORO colorimetric assay. HepG2 cells were pre-incubated with the bioactives prior to FFAs treatment at an optimum time of 2 hours as derived after three repeated experiments (data not shown).

\section{Fluorimetric imaging with Nile red and Hoechst-3342 staining}

Fluorescent dye, Nile red (Sigma-Aldrich, St. Louis, MO, USA) and Hoechst-33342 (Sigma-Aldrich, St. Louis, MO, USA) were used for detection of intracellular lipids and nuclei respectively. HepG2 cells $\left(5 \times 10^{4}\right.$ cells/well) treated on $8 \mathrm{~mm}$ sterile cover slip in a 12 well plates were fixed (4\% paraformaldehyde) and stained for 10 minutes in dark. The plates were then washed and mount- ed on a glass slide with a drop of polyvinyl alcohol and phenylenediamine mixture. The cover slips were later mounted on the glass slide with the cell surface facing the mowiol solution. The slides were allowed to dry and the images of the in vitro fatty liver model with pretreated phytoactives were captured using confocal microscope at 40x. The corrected total cell fluorescence of Nile red was measured using Image J software.

\section{Quantitative Real time-Polymerase chain reaction (PCR)}

Post treatment, HepG2 cells $\left(1 \times 10^{5}\right.$ cells/well) were lysed using $1 \mathrm{~mL}$ Trizol reagent (Ambion, Life technologies, Waltham, MA, USA). Total RNA was isolated and complementary DNAs (cDNAs) were synthesized using CDNA reverse transcription kit as per manufacturer instructions using PCR thermal cycler (Applied Biosystems Inc-ABI, Waltham, MA, USA). ${ }^{16}$ Quantitative detection of fatty acid transport protein 5 (FATP5), stearoyl CoA desaturase $(S C D)$, peroxisome proliferator activated receptor $\alpha$ (PPAR $\alpha)$, carnitine palmitoyltransferase 1 (CPT1), forkhead box protein 01 (FOX01), phosphoenolpyruvate carboxykinase (PEPCK) and $\beta$-actin were performed as shown in Table 1. Primer sequence of each gene synthesized by Sigma-Aldrich, India was used. RT-PCR amplification was performed in the total volume of $20 \mu \mathrm{L}$ comprising of $10 \mu \mathrm{L}$ SYBR Green $(2 \times), 1 \mu \mathrm{L}$ each of forward and reverse primer $(10 \mu \mathrm{M}), 4 \mu \mathrm{L}$ nuclease-free water and $4 \mu \mathrm{L}$ cDNA solution. PCR was run for 35 cycles using ABI-7500 Fast RT-PCR

Table 1. Gene-special primers used for real-time polymerase chain reaction

\begin{tabular}{|c|c|c|c|}
\hline Gene & Pathway & Sequence $\left(5^{\prime} \rightarrow 3^{\prime}\right)$ & Gene Bank no./ref \\
\hline Human FATP5 & Fatty acid uptake & $\begin{array}{l}\text { Forward: TGATGGGACTTGTCGTTGG } \\
\text { Reverse: CCAGAAGCAGGAAGTAGAGAAC }\end{array}$ & NM_012254 \\
\hline Human SCD & Lipid synthesis & $\begin{array}{l}\text { Forward: AGTTCTACACCTGGCTTGG } \\
\text { Reverse: GTTGGCAATGATCAGAAAGAGC }\end{array}$ & NM_005063 \\
\hline Human PPARa & Fatty acid oxidation & $\begin{array}{l}\text { Forward: CAATGCACTGGAACTGGATGA } \\
\text { Reverse: GTTGCTCTGCAGGTGGAGTCT }\end{array}$ & NM_001001928 \\
\hline Human CPT1 & Fatty acid oxidation & $\begin{array}{l}\text { Forward: TCCAACTCACATTCAGGCAG } \\
\text { Reverse: TTAAACATCCGCTCCCACTG }\end{array}$ & NM_001031847.2 \\
\hline Human FOXO1 & Gluconeogenesis & $\begin{array}{l}\text { Forward: CTACGAGTGGATGGTCAAGAG } \\
\text { Reverse: ATGAACTTGCTGTGTAGGGAC }\end{array}$ & NM_002015 \\
\hline Human PEPCK & Gluconeogenesis & $\begin{array}{l}\text { Forward: GAGAATACTGCCACACTGACC } \\
\text { Reverse: CCGCTGAGAAGGAGTTACAATC }\end{array}$ & NM_001018073 \\
\hline Human $\beta$-actin & Housekeeping gene & $\begin{array}{l}\text { Forward: GTCTTCCCCTCCATCGT } \\
\text { Reverse: CGTCCCCACATGGAAT }\end{array}$ & NM_007393.5 \\
\hline
\end{tabular}

FATP5, fatty acid transport protein 5; SCD, stearoyl CoA desaturase; PPARa, peroxisome proliferator activated receptor a; CPT1, carnitine palmitoyltransferase 1; FOX01, forkhead box protein 01; PEPCK, phosphoenolpyruvate carboxykinase. 
system. The conditions used were; denaturation at $95^{\circ} \mathrm{C}$ for 5 minutes, $35-40$ cycles of $95^{\circ} \mathrm{C}$ for 15 seconds and annealing at $60^{\circ} \mathrm{C}$ for 1 minute, extension at $72^{\circ} \mathrm{C}$ for 1 minute and a final extension at $72^{\circ} \mathrm{C}$ for 5 minutes. The quantitative cycle (CQ) value of each gene was normalized with that of $\beta$-actin.

\section{Western blot}

The treated HepG2 $\left(5 \times 10^{5}\right.$ cells/well) cells were harvested in RIPA buffer supplemented with anti-protease and anti-phosphate inhibitor cocktails (Sigma-Aldrich, St. Louis, MO, USA). Protein was quantified using BCA protein assay Kit (Thermo Fisher Scientific, Waltham, MA, USA). SDS-PAGE was performed using $40 \mu \mathrm{g}$ of protein sample on a 10\% denaturing SDS gel and transferred on polyvinylidene fluoride membrane (Bio-Rad Laboratories, Inc., Hercules, CA,USA). ${ }^{17}$ The blots were incubated with specific primary antibodies; anti-sterol regulatory element binding protein 1 (anti-SREBP-1) (Santacruz Biotechnology, Dallas, TX, USA, sc-366) (dilution 1:1,000), anti-PEPCK (Cell Signaling technology, Danvers, MA, USA, 6924) (dilution 1:1,000) and anti $\beta$-actin (Santacruz Biotechnology, Dallas, TX, USA, sc-81178) (dilution 1:1,000) followed by respective secondary antibody. The blot images were later captured using ChemiDoc'TM XRS (Bio-Rad, Hercules, CA, USA). The blot intensity was quantified using Image J software.
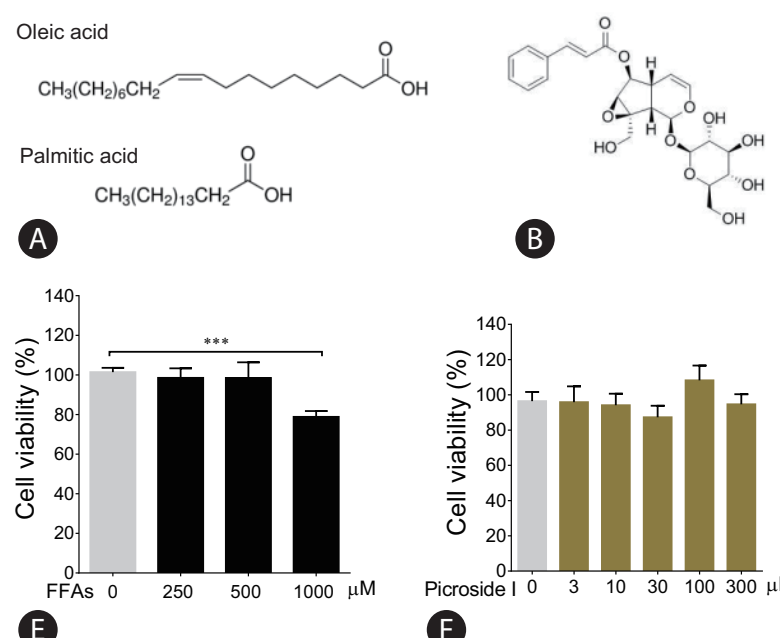

B
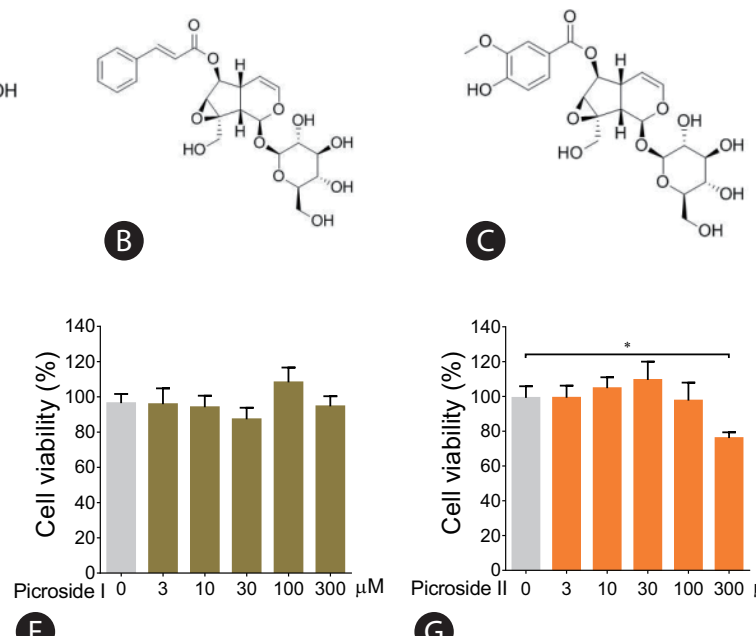

\section{Statistical analysis}

\section{RESULTS}

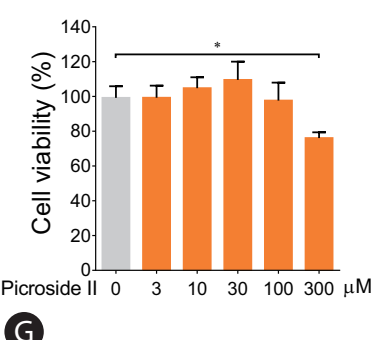

G

C

•

The results are shown as the means \pm standard errors of mean (SEM). Differences were evaluated by one and two way analysis of variance (ANOVA) using Graph Pad Prism, Version 5 (GraphPad Software, Inc., La Jolla, CA, USA). A $P$-value $<0.05\left(^{*}\right),<0.01\left(^{* *}\right)$ and $\left.<0.0011^{* * *}\right)$ was considered to be statistically significant.

\section{Cytotoxic effect of FFAs, picroside I and II}

The molecular structure of FFAs (oleic and palmitic acid), and phytoactives (picroside I, II and silibinin) are shown in Fig. 1A-D. HepG2 cells were treated with different concentrations of FFAs, 250 to $1,000 \mu \mathrm{M}$ for 24 hours, to test for cytotoxicity. The FFAs mixture (oleic acid:palmitic acid/2:1) did not show any cellular damage at a concentration of 250 and $500 \mu \mathrm{M}$. At 1,000 $\mu \mathrm{M}$, $21.2 \%$ cell death was observed. Since our aim was to study fatty liver model with minimal cytotoxicity, FFAs concentration of 250 and $500 \mu \mathrm{M}$ was used for further work (Fig. 1E). The phytoactives, picroside I, II and silibinin (positive control), were also tested for their cytotoxic effects in HepG2 cells in the concentration range of 3 to $300 \mu \mathrm{M}$. Picroside I did not show any cell damage in HepG2 cells at a concentration range of 3 to $300 \mu \mathrm{M}$ (Fig. 1F). On the other hand, picroside II inhibited cell growth by $24 \%$ at

E

Figure 1. Cytotoxic effect of FFAs and picroside I and II in HepG2 cells: The chemical structure of FFAs (A), picroside I (B), picroside II (C) and silibinin (D), HepG2 cells were loaded with different concentrations of FFAs (E), picroside I (F), picroside II (G), and silibinin (H) for 24 hours. Cytotoxicity was measured via MTT assay. Values are expressed as mean \pm SEM from four independent replicates. FFAs, free fatty acids; $S E M$, standard errors of mean. ${ }^{*}<<0.05$; ${ }^{* * * *} P<0.001$. 
higher concentration of $300 \mu \mathrm{M}$ (Fig. 1G). For both the phytoactives, optimal cell viability was observed up to $10 \mu \mathrm{M}$ beyond which, some amount of cell death was observed. As reported earlier, silibinin was also found to inhibit cell growth by $23 \%$ at 300 $\mu \mathrm{M}$ (Fig. 1H). ${ }^{14}$ Therefore, a concentration of $10 \mathrm{uM}$ was selected for phytoactive pretreatment.

\section{Lipid accumulation in HepG2 cells using FFAs}

After treating HepG2 cells with 250 and $500 \mu \mathrm{M}$ of FFAs for 20 hours, lipid accumulation was observed using ORO and Nile red stain. The morphological observations showed an increase in lipid accumulation with an increase in FFAs concentration (Fig. 2A). The quantitative analysis confirmed that the lipid accumulation was significantly higher at $500 \mu \mathrm{M}$ (Fig. 2B, C). There was 14\% and $50 \%$ increase in intracellular fat accumulation at $250 \mu \mathrm{M}$ (ORO stain) and $500 \mu \mathrm{M}$ respectively compared to control cells.
The FFAs concentration of $500 \mu \mathrm{M}$, which resulted in highest lipid accumulation, was chosen for further analysis.

\section{Picroside II attenuates intracellular lipid accumulation}

Two hours prior to FFAs challenge, the HepG2 cells were pretreated with picroside I, II and silibinin. Picroside I did not show any inhibitory activity on lipid accumulation and was thus not studied further. It was observed that picroside II reduced cellular lipids by $30 \%$ compared to FFAs treated group. Silibinin, a known hepatoprotective molecule, caused $22 \%$ reduction in lipid accumulation (Fig. 3).

\section{Picroside II decreases transcription of genes involved in fatty acid uptake and synthesis}

In order to examine the impact of FFAs loading on HepG2 cells,
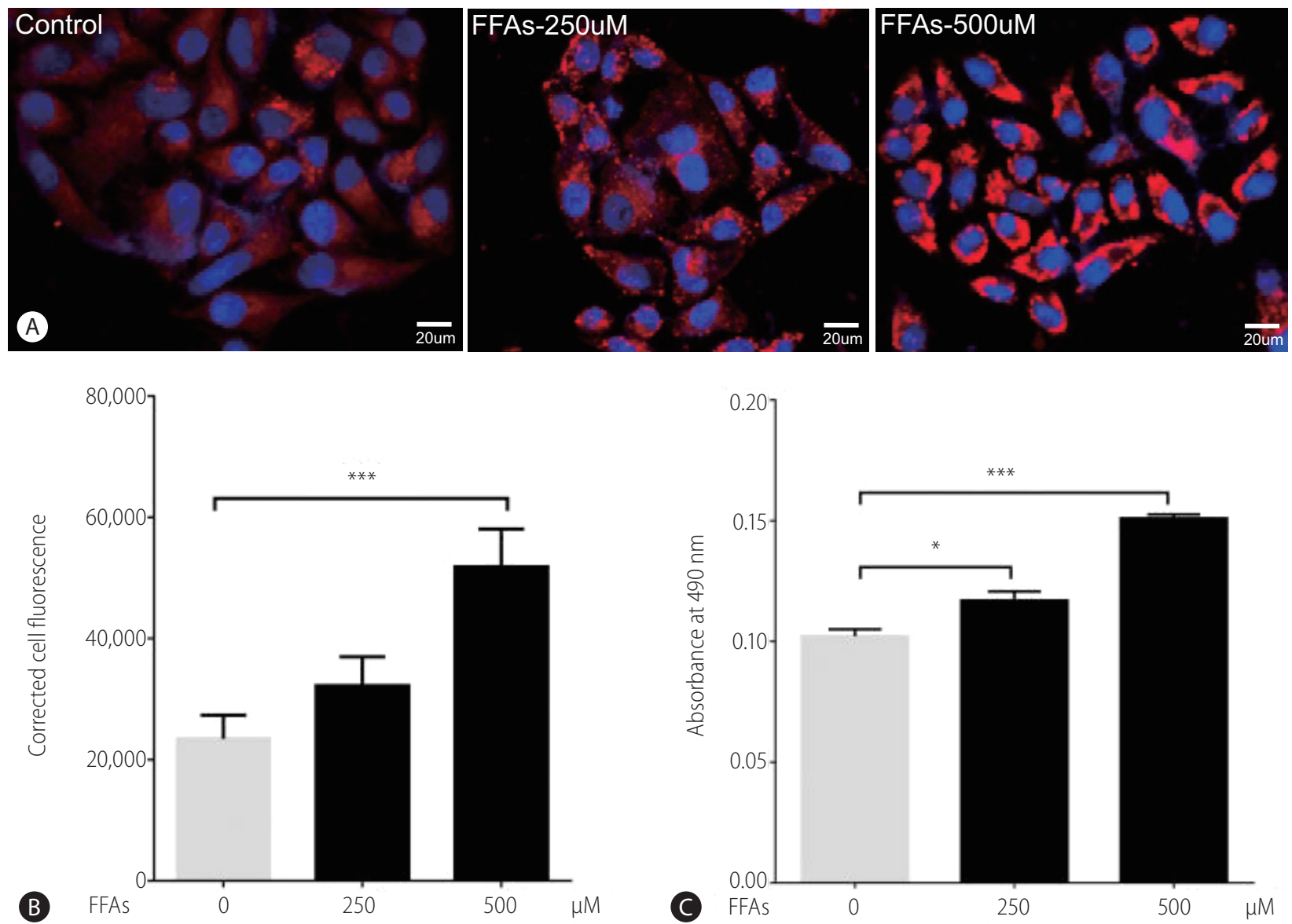

Figure 2. Effect of FFA challenge on lipid accumulation: HepG2 cells were loaded with FFA mixtures ( 250 and $500 \mu M)$ for 20 hours. Nile red and Hoechst-33342 staining (magnification 40X) (A), Nile red fluorescence intensity (B), and ORO colorimetric assay (C). The values are expressed as mean \pm SEM from six independent replicates. FFAs, free fatty acids; ORO, Oil Red O; SEM, standard errors of mean. ${ }^{*} P<0.05{ }^{* * *} P<0.001$. 


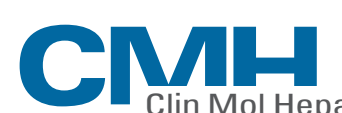

Volume 24 Number_1 March 2018
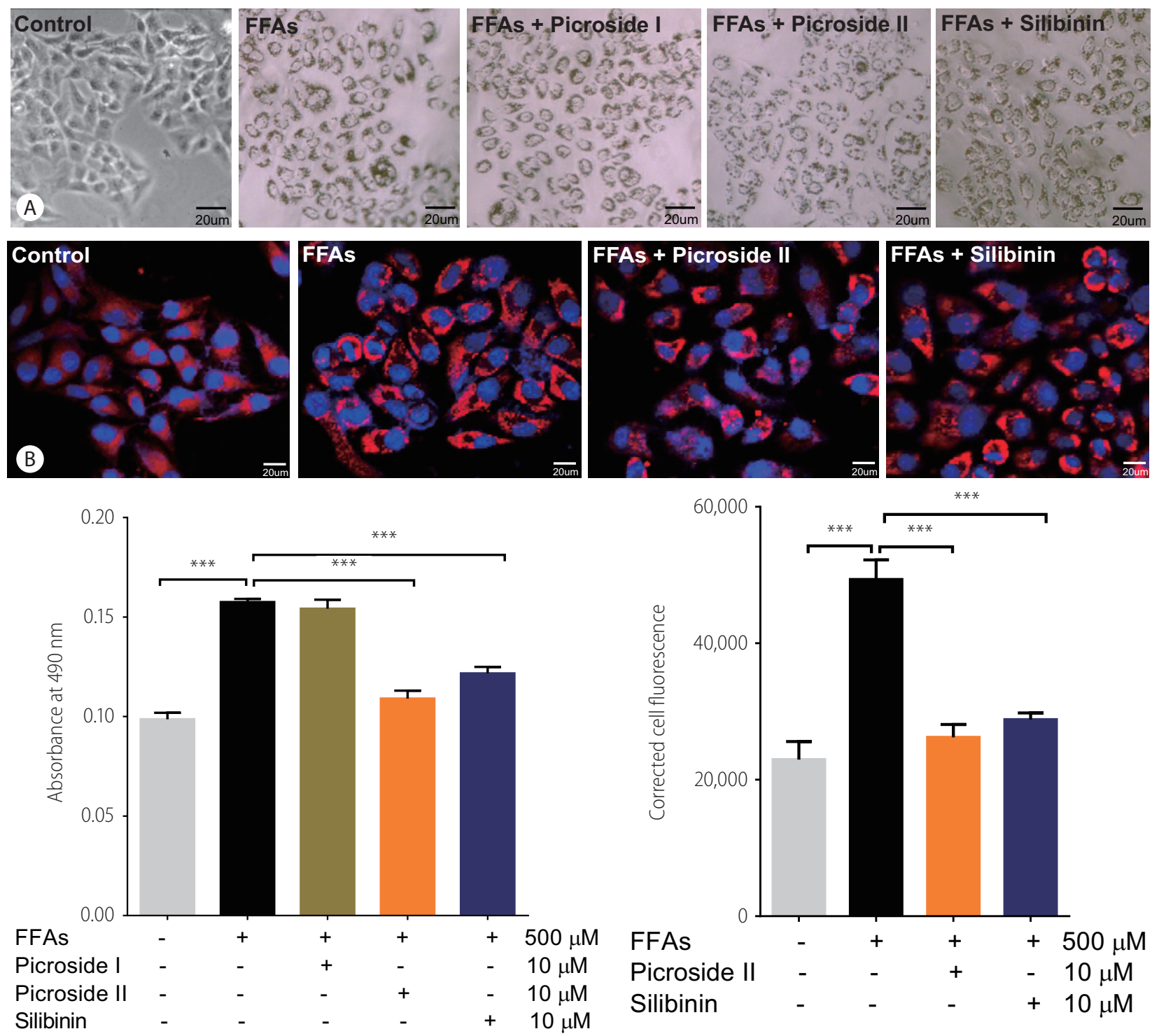

C

(D)

Figure 3. Picroside II attenuates FFA-mediated lipid accumulation: HepG2 cells were pretreated with picroside II and silibinin at a concentration of 10 $\mu \mathrm{M}$ for 2 hours, followed by FFA $(500 \mu \mathrm{M})$ challenge for another 20 hours. ORO staining (10X) (A), Nile red and Hoechst-33342 staining (B), ORO colorimetric assay (C), and Nile red fluorescence intensity (D). Values are expressed as mean \pm SEM from six independent replicates. FFAs, free fatty acids; ORO, Oil Red O; SEM, standard errors of mean. ${ }^{* * *} P<0.001$.

we investigated the expression of the genes involved in fatty acid metabolism. There was a 2-fold rise in the mRNA expression of FATP5 in FFAs treated cells as compared to control cells (Fig. 4A). On pretreatment with picroside II and silibinin, there was a significant downregulation in the expression of FATP5 compared to FFAs treated HepG2 cells.

Apart from an increase in FATP5 levels in FFAs treated group, a 2 -fold rise in the mRNA expression of SCD was also observed (Fig.
4B). Concomitantly, there was an increase in SREBP-1 protein expression (Fig. 4C). Both picroside II and silibinin were found to significantly downregulate these lipogenic genes. There were no changes in the $\beta$-oxidation pathways as seen in the mRNA expression of CPT1 and PPAR $\alpha$ in the FFAs treated group (Supplementary Fig. 1A, B). Picroside II and silibinin did not show any significant effect on the $\beta$-oxidation pathway. 


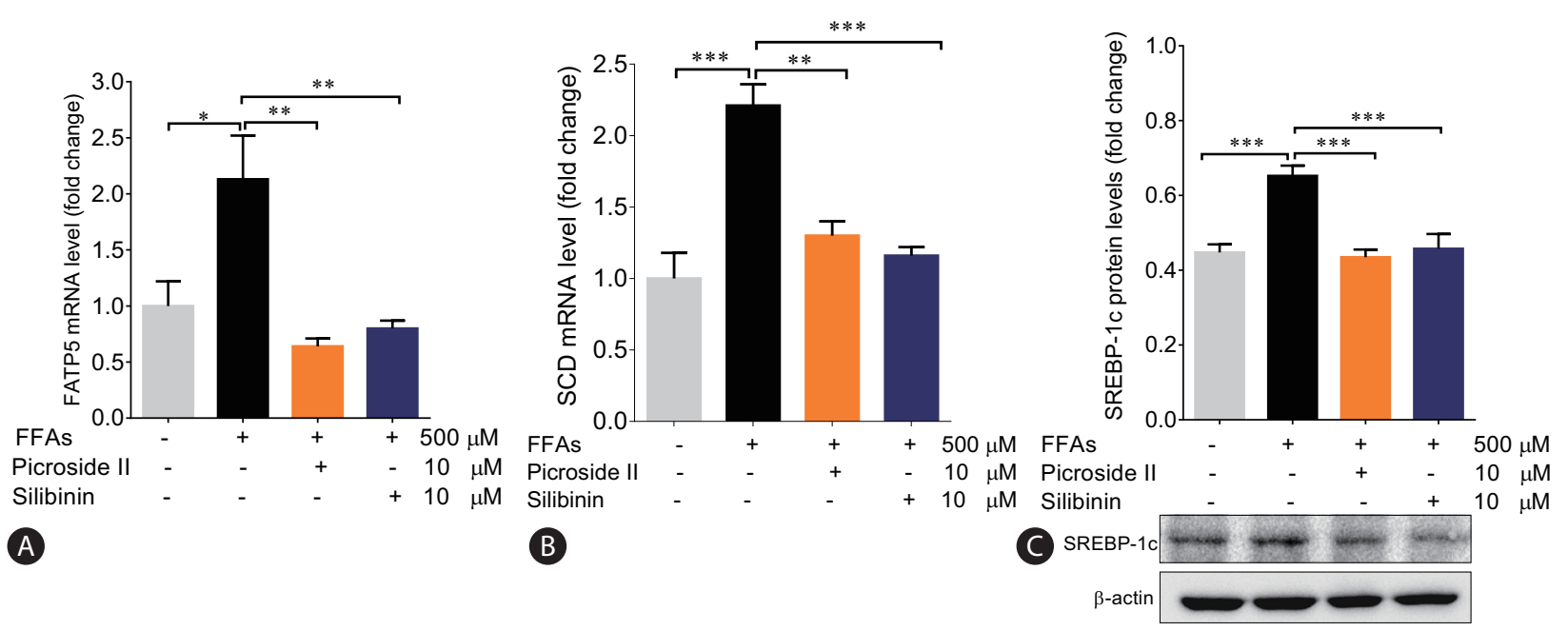

Figure 4. Picroside II mitigates the transcription of genes involved in fatty acid uptake and synthesis: HepG2 cells were pretreated with picroside II and silibinin at a concentration of $10 \mu \mathrm{M}, 2$ hours prior to FFA (500 $\mu \mathrm{M})$ loading for 20 hours followed by RT-PCR analysis of FATP5 (A), SCD (B) and Western blot analysis of SREBP-1 (C). Values are expressed as mean \pm SEM from four independent replicates. FFAs, free fatty acids; RT-PCR, reverse transcription polymerase chain reaction; FATP5, fatty acid transport protein 5; SCD, Stearoyl COA desaturase; SREBP-1, sterol regulatory element binding protein-1; SEM, standard errors of mean. ${ }^{*} P<0.05 ;{ }^{* * *} P<0.01 ;{ }^{* * * *} P<0.001$.

\section{Picroside Il decreased activity of gluconeogenic genes}

The mRNA expression of FOXO1 and PEPCK were significantly increased in the FFAs treated cells as compared to control cells (Fig. 5A, B). The upregulation in the protein expression of PEPCK was also observed (Fig. 5C). Pretreatment with picroside II and silibinin significantly downregulated the mRNA expression of FOXO1 and PEPCK compared to the FFAs treated HepG2 cells.

\section{DISCUSSION}

Considering the complexity of NAFLD and its rising prevalence globally, it is vital to find effective therapeutic modalities for its treatment. The current pharmacotherapies available for patients with NAFLD include thiazolidinediones, ursodeoxycholic acid, clofibrate, gemfibrozil, vitamin E, metformin, and betaine. ${ }^{6}$ However, none of them have been proven to be efficient in clinical practice. Their limited efficacy in treating NAFLD, which involves deregulation of multiple pathways, could be because of their very specific target protein. ${ }^{18}$ Additionally, life style management is also an alternative therapy used for treating NAFLD. Since the changes with diet and exercise are found to be short lived, long-term sustainability is a major challenge due to poor patient compliance. 19,20

In NAFLD, an increase in hepatic FFAs uptake, lipid synthesis, impaired $\beta$-oxidation, and decrease in lipid export facilitates ac- cumulation of fat in the liver. ${ }^{21}$ Hence, modulating the molecular mechanisms involved in hepatic lipid accumulation would provide competent therapeutic targets suitable for mitigating the scourge of NAFLD.

Over the past few years, phytochemicals from plants have received increasing attention for determining their activity and safety in basic model and clinical conditions. ${ }^{22}$ With the use of Reverse pharmacology (RP) as a novel path to drug discovery from natural products, bedside observational hits can lead for bench side-exploratory studies (in vitro and in vivo) and for subsequent use in clinical research. ${ }^{23}$ Our group has been studying $P$. kurroa extensively for its hepatoprotective activity using RP. ${ }^{10-13}$ In the present study too, we found that picroside $\mathrm{II}$, an active constituent of $P$. kurroa, has the potential for halting lipid accumulation in NAFLD. Earlier, our group has demonstrated $P$. kurroa's hepatoprotective activity in an in vivo Wistar rat model of NAFLD. ${ }^{24}$ In this model, $P$. kurroa reversed hepatic fatty acid infiltration by decreasing liver lipid content and serum TG and cholesterol levels. P. kurroa also lowered alanine amino transferase and alkaline phosphatase levels, thereby signifying its anti-inflammatory activity in preventing NAFLD's progression to NASH. However, in the above studies, the mechanism(s) by which $P$. kurroa's constituents exerted their effect was not fully addressed. In support of our earlier work, the present study demonstrates that picroside II, decreased fatty acid accumulation by inhibiting FFAs uptake and synthesis.

Primary hepatocytes, derived from human liver samples, are an 


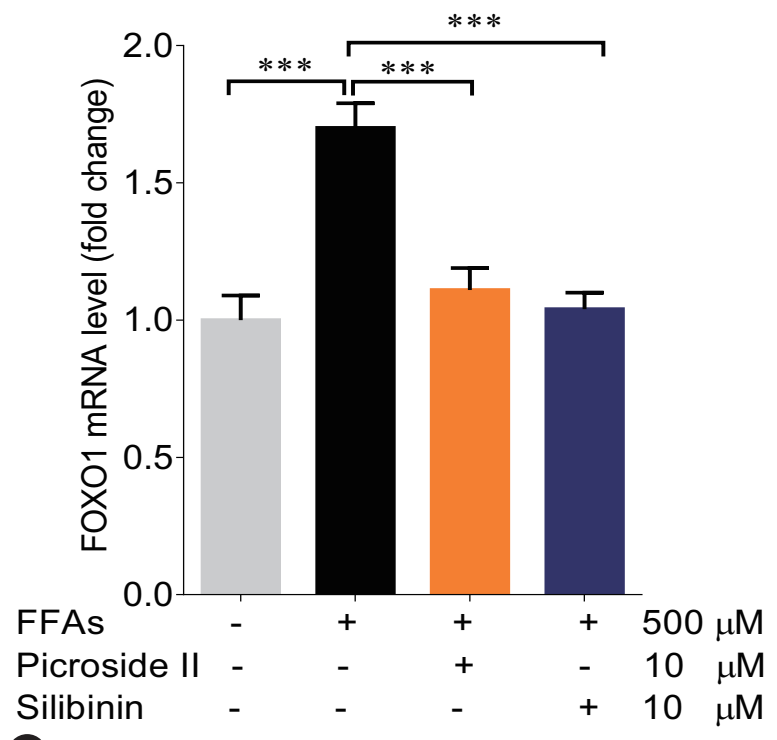

A

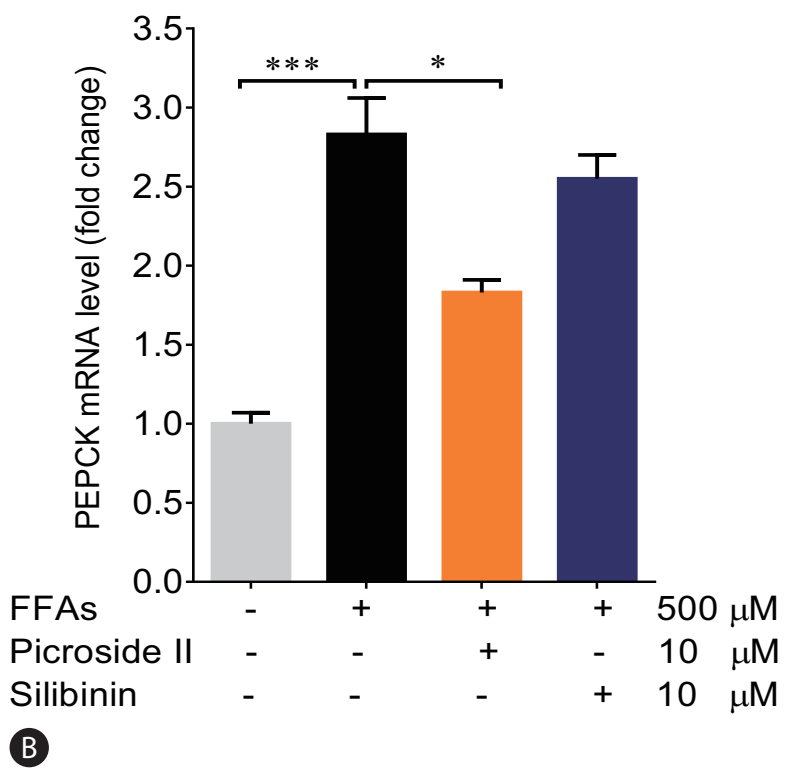

ideal in vitro model for studying hepatosteatosis. However, the paucity of obtaining normal clinical liver samples limits their use. As a consequence, the use of HepG2 cells as an alternative cellular model is considered acceptable. ${ }^{25}$ Since oleic and palmitic acids are found in abnormally high concentration in liver TGs of steatotic patients, steatosis was simulated in HepG2 cells using these fatty acids. ${ }^{26}$ We investigated the expression of genes involved in fatty acid uptake, lipogenesis, and utilization via $\beta$-oxidation. Several investigations have shown that FFAs enter the hepatocytes via facilitated transport via FATP5. ${ }^{27}$ FATP5 is a membrane-bound transport protein causing uptake of long chain FFAs across the

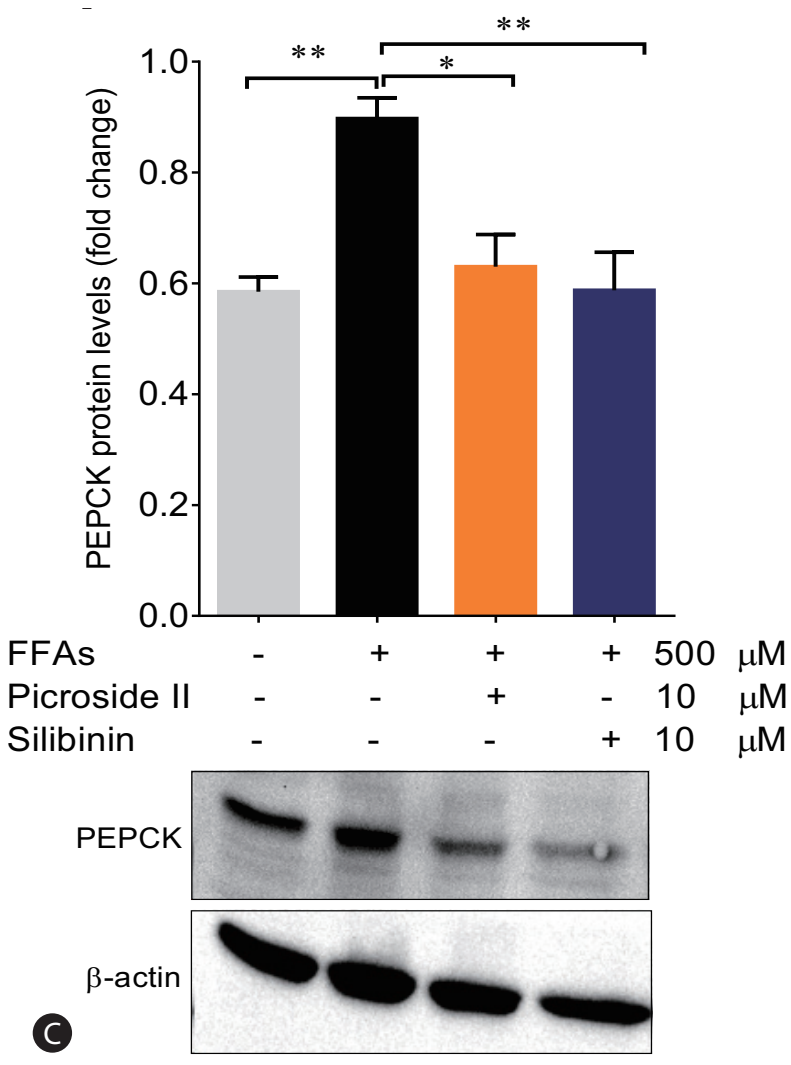

Figure 5. Picroside II decreases the expression of gluconeogenic genes: HepG2 cells were pretreated with picroside II and silibinin at a concentration of $10 \mu \mathrm{M} 2$ hours prior to FFA ( $500 \mu \mathrm{M})$ loading for 20 hours followed by RT-PCR analysis of FOXO1 (A), PEPCK (B), and Western blot analysis of PEPCK (C). Values are expressed as mean \pm SEM from four independent replicates. FFAs, free fatty acids; RT-PCR, reverse transcription polymerase chain reaction; FOXO1, forkhead box protein O1; PEPCK, phosphoenolpyruvate carboxykinase; SEM, standard errors of mean. " $P<0.05$; ${ }^{* * *} P<0.01$; ${ }^{* * *} P<0.001$.

plasma membrane. An increase in the expression of FATP5 has been reported in subjects with simple steatosis. ${ }^{28}$ In our study too, we found a significant increase in the expression of FATP5 in response to FFAs treatment alone, suggesting an increase in hepatic FFAs uptake. Studies have shown that decreasing the expression of FATP5 could reduce lipid deposition in hepatocytes, in turn reversing steatosis. Also, knockdown of FATP5 in mice fed with a high fat diet reduced hepatic FFAs uptake, lipid accumulation, and decreased blood glucose levels. ${ }^{29}$ We observed a remarkable reduction in the expression of FATP5 in picroside II intervention group, compared to FFAs treated group. This shows that picroside 


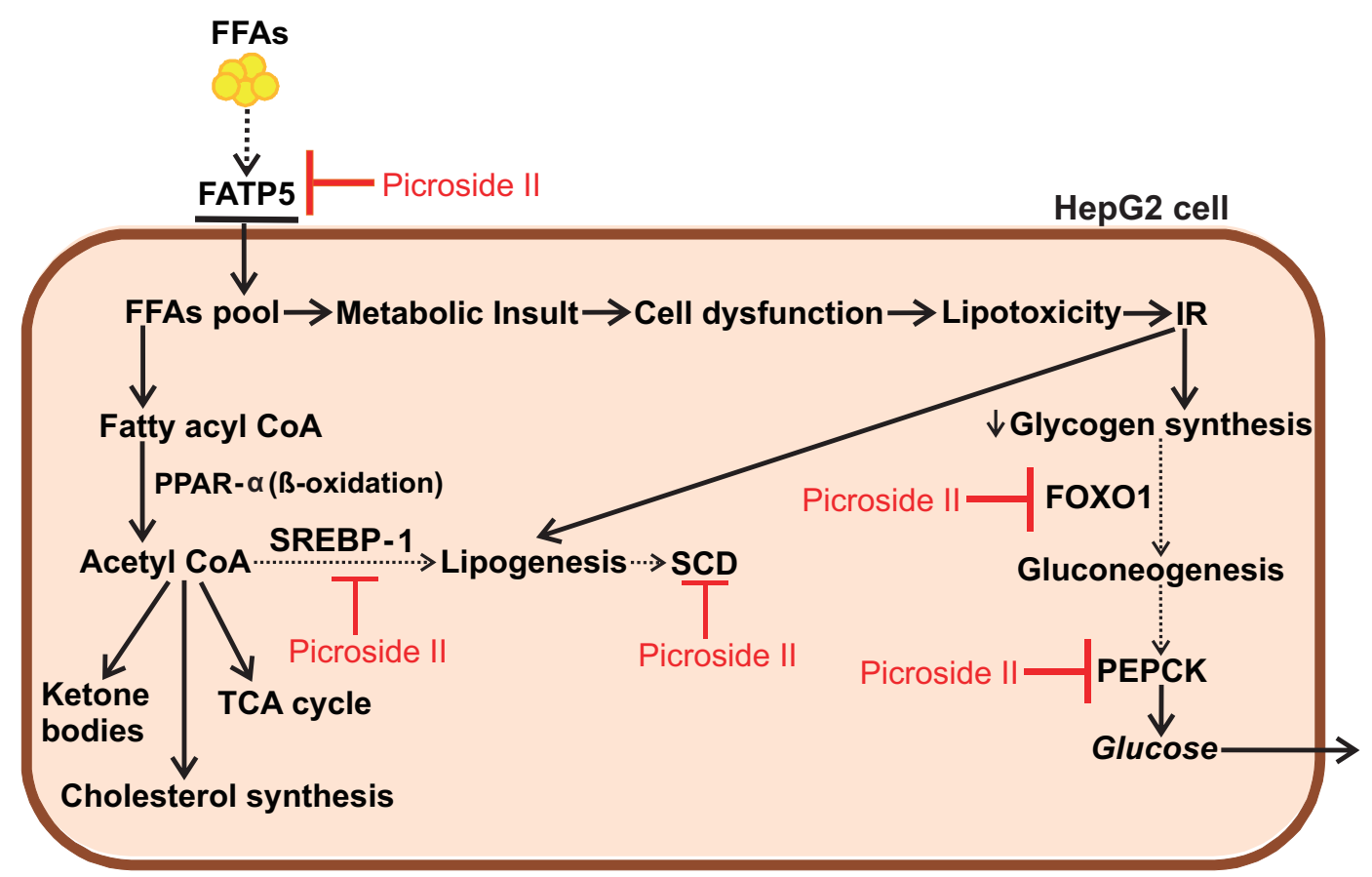

Figure 6. Proposed model for the protective action of picroside II in FFA-loaded HepG2 cells: Picroside II attenuated FFA accumulation in HepG2 cells via downregulation of FATP5, SREBP-1 and SCD, decreasing fatty acid uptake and lipid synthesis. Picroside II was also found to decrease the expression of FOXO1 and PEPCK resulting in decreased gluconeogenesis. Black dotted arrows indicates decrease in the expression of genes upon picroside II pretreatment. Red arrows indicates inhibitory activity of picroside II on the genes examined. FFAs, free fatty acids; FATP5, fatty acid transport protein 5; SREBP-1, sterol regulatory element binding protein-1; SCD, stearoyl CoA desaturase; FOXO1, forkhead box protein O1; PEPCK, phosphoenolpyruvate carboxykinase; IR, insulin resistance; CoA, coenzyme A; PPAR-a, peroxisome proliferator activated receptor a; TCA, tricarboxylic acid cycle.

II attenuates the uptake of hepatic FFAs by decreasing the expression of FATP5 gene. Interestingly, as compared to silibinin, picroside II showed a greater trend in decreasing FFAs uptake and it needs to be studied further. Besides hepatic FFAs uptake, increased lipogenesis is known to contribute towards TG accumulation in the hepatocytes via activation of transcription factor SREBP-1. ${ }^{30}$ This in turn stimulates the expression of fatty acid synthase, acetyl CoA carboxylase and SCD causing an increase in lipogenesis. ${ }^{31}$ In our FFAs treated HepG2 cells, we found a significant rise in the expression of SREBP-1 and SCD indicating an increase in formation and storage of TG in hepatic cytoplasm. Picroside II altered SREBP-1 and SCD dependent lipogenesis similar to silibinin. The decrease in the expression of SRBEP-1 and SCD highlights picroside II's anti-lipogenic activity.

There is growing evidence that impaired mitochondrial $\beta$-oxidation contributes to increased liver lipid accumulation. ${ }^{32}$ PPAR $\alpha$, a nuclear receptor expressed in liver, exerts its transcriptional effects on fatty acid oxidation genes. PPAR $\alpha$ augments the transcription of CPT1, which is a rate limiting enzyme involved in fatty acid oxidation. ${ }^{33} \mathrm{~A}$ decrease in PPAR $\alpha$ and CPT1 limits the ability of the hepatocytes to oxidize FFAs leading to steatosis. Therefore, by modulating the expression of PPAR $\alpha$ and CPT1 genes, hepatic steatosis can be alleviated. In our study, picroside II as well as silibinin did not cause any significant change in the $\beta$-oxidation pathway.

Hyperglycemia and/or insulin resistance are observed in patients with NAFLD increasing their probability to develop type 2 diabetes (T2D). ${ }^{34}$ In these cases, an increase in hepatic gluconeogenesis is observed due to increased expression of FOXO1 and PEPCK. ${ }^{35}$ We observed that picroside II reduced the expression of FOX01 and PEPCK significantly, like silibinin. These results underscore the potential of picroside II in mitigating the development of T2D in patients with NAFLD by decreasing gluconeogenic genes.

In the present study, picroside II attenuates hepatic lipid accumulation in HepG2 cells by decreasing FFAs uptake through FATP5, lipid synthesis via SREBP-1, and SCD. Further hepatic gluconeogenesis was downregulated with decrease in the expression of FOX01 and PEPCK (Fig. 6). The activity of picroside II was found to be comparable to silibinin. The current findings suggest the need to study the activity of picroside II in other in vitro (pri- 
mary hepatocytes, hepatic spherules or dual cell cultures with Kupffer cells) and in vivo models of NAFLD. Silibinin is a widely used hepatoprotective compound shown to prevent progressive liver injury by inhibiting lipotoxicity via modulation of oxidative stress and $N F \kappa B .{ }^{36}$ Since, overloading the hepatocytes with fatty acids increases oxidative stress, inflammation and mitochondrial dysfunction; it raises the need for further exploration of the efficacy of $P$. kurroa's phytoactive in the NAFLD model system. These factors would be relevant to the progressive pathophysiology of NASH leading to chronic sequelae.

Thus, our study shows that picroside II and silibinin remarkably decreases intracellular lipid content in FFAs treated HepG2 cells via modulation of free fatty acid uptake, lipogenesis and gluconeogenesis. Picroside II's protective effect on inhibiting lipid accumulation highlights it as a potential molecular entity in reversing fatty liver.

\section{Author's contribution}

Conceptualization, Hiteshi Dhami-Shah and Ashok Vaidya; Investigation, Hiteshi Dhami-Shah (for Cell culture, ORO staining, MTT, Confocal imaging, RT-PCR, Western blot), Shiny Abhijit (for Confocal imaging), and Srividhya Raghavan (for Cell culture); Original draft, Hiteshi Dhami-Shah, Ashok Vaidya, Rama Vaidya, and Shobha Udipi; Funding acquisition, Hiteshi Dhami-Shah; Supervision, Muthuswamy Balasubramanyam, Ashok Vaidya, Rama Vaidya, Shobha Udipi, and Viswanathan Mohan.

\section{Acknowledgements}

We thank the Department of Science \& Technology, Government of India, for the research grant under Women Scientist-A program (SR/WOS-A/LS-1135/2014). We also thank S.N.D.T Women's University, Madras Diabetes Research Foundation and Kasturba Health Society for the support in terms of infrastructure and encouragement. A special thanks to Dr. Tandrika Chattopadhyay (Tata Institute of Fundamental Research) for guiding us with writing the manuscript.

\section{Conflicts of Interest}

The authors have no conflicts to disclose.

\section{SUPPLEMENTARY MATERIALS}

Supplementary materials are available at Clinical and Molecular Hepatology website (http://www.e-cmh.org).

\section{REFERENCES}

1. Green CJ, Hodson L. The influence of dietary fat on liver fat accumulation. Nutrients 2014;6:5018-5033.

2. Schaffer JE. Lipotoxicity: when tissues overeat. Curr Opin Lipidol 2003;14:281-287.

3. Chalasani N, Younossi Z, Lavine JE, Diehl AM, Brunt EM, Cusi K, et al. The diagnosis and management of non-alcoholic fatty liver disease: practice guideline by the American Gastroenterological Association, American Association for the Study of Liver Diseases, and American College of Gastroenterology. Gastroenterology 2012;142:1592-1609.

4. Sanyal AJ. Mechanisms of disease: pathogenesis of nonalcoholic fatty liver disease. Nat Clin Pract Gastroenterol Hepatol 2005;2:46-53.

5. Rui L. Energy metabolism in the liver. Compr Physiol 2014;4:177-197.

6. Tolman KG, Dalpiaz AS. Treatment of non-alcoholic fatty liver disease. Ther Clin Risk Manag 2007;3:1153-1163.

7. Gulabkunvarba Ayurvedic Society. Charak-Samhita. Jamnagar: Gulabkunvarba Ayurvedic Society, 1949:1600-1607.

8. Pandey VN, Chaturvedi GN. Effect of indigenous drug kutaki on bile after producing biliary fistula in dogs. Indian J Med Res 1970;5:1-24.

9. Antarkar DS, Tathed PS, Vaidya AB. A pilot phase II trial with arogya-wardhani and Punarnavadi-Kwath in viral hepatitis. Panminerva Med 1978;20:157-163.

10. Dwivedi Y, Rastogi R, Chander R, Sharma SK, Kapoor NK, Garg NK, et al. Hepatoprotective activity of picroliv against carbon tetrachloride induced liver damage in rats. Indian J Med Res 1990;92:195-200.

11. Dwivedi Y, Rastogi R, Garg NK, Dhawan BN. Prevention of paracetamolinduced hepatic damage in rats by picroliv, the standardized active fraction from Picrorhiza kurroa. Phytother Res 1991;5:115-119.

12. Dwivedi Y, Rastogi R, Sharma SK, Garg NK, Dhawan BN. Picroliv affords protection against thioacetamide-induced hepatic damage in rats. Planta Med 1991;57:25-28.

13. Visen PK, Shukla B, Patnaik GK, Dhawan BN. Prevention of galactosamine-induced hepatic damage by picroliv: study on bile flow and isolated hepatocytes (ex vivo). Planta Med 1993;59:37-41.

14. Varghese L, Agarwal C, Tyagi A, Singh RP, Agarwal R. Silibinin efficacy against human hepatocellular carcinoma. Clin Cancer Res 2005;11:8441-8448.

15. Cousin SP, Hügl SR, Wrede CE, Kajio H, Myers MG Jr, Rhodes CJ. Free fatty acid-induced inhibition of glucose and insulin-like growth factor 1-induced deoxyribonucleic acid synthesis in the pancreatic beta-cell line INS-1. Endocrinology 2000;142:229-240.

16. Zanoni I, Ostuni R. mRNA expression analysis by real-time PCR. Nature Protocol Exchange 2009:138. Published online 18 June 2009. doi:10.1038/nprot.2009.138

17. Mahmood T, Yang PC. Western blot: technique, theory, and trouble shooting. N Am J Med Sci 2012;4:429-434. 
18. Malhi H, Guicciardi ME, Gores GJ. Hepatocyte death: a clear and present danger. Physiol Rev 2010;90:1165-1194.

19. Johnson NA, Sachinwalla T, Walton DW, Smith K, Armstrong A, Thompson MW, et al. Aerobic exercise training reduces hepatic and visceral lipids in obese individuals without weight loss. Hepatology 2009;50:1105-1112.

20. Catalano D, Trovato GM, Martines GF, Randazzo M, Tonzuso A. Bright liver, body composition and insulin resistance changes with nutritional intervention: a follow-up study. Liver Int 2008;28:1280-1287.

21. Koutsari C, Mundi MS, Ali AH, Patterson BW, Jensen MD. Systemic free fatty acid disposal into very low-density lipoprotein triglycerides. Diabetes 2013;62:2386-2395.

22. Yan C, Sun W, Wang $X$, Long J, Liu $X$, Feng $Z$, et al. Punicalagin attenuates palmitate-induced lipotoxicity in HepG2 cells by activating the Keap1-Nrf2 antioxidant defense system. Mol Nutr Food Res 2016;60:1139-1149.

23. Vaidya AD. Reverse pharmacology-A paradigm shift for drug discovery and development. Curr Res Drug Discovery 2014;1:39-44.

24. Shetty SN, Mengi S, Vaidya R, Vaidya AD. A study of standardized extracts of Picrorhiza kurroa Royle ex Benth in experimental nonalcoholic fatty liver disease. J Ayurveda Integr Med 2010;1:203-210.

25. Feldstein AE, Canbay A, Guicciardi ME, Higuchi H, Bronk SF, Gores GJ. Diet associated hepatic steatosis sensitizes to Fas mediated liver injury in mice. J Hepatol 2003;39:978-983.

26. Gómez-Lechón MJ, Donato MT, Martínez-Romero A, Jiménez N, Castell JV, O'Connor JE. A human hepatocellular in vitro model to investigate steatosis. Chem Bio Interact 2007;165:106-116.

27. Pohl J, Ring A, Hermann T, Stremmel W. Role of FATP in parenchymal cell fatty acid uptake. Biochim Biophys Acta 2004;1686:1-6.

28. Mitsuyoshi H, Yasui $K$, Harano $Y$, Endo M, Tsuji K, Minami M, et al. Analysis of hepatic genes involved in the metabolism of fatty acids and iron in nonalcoholic fatty liver disease. Hepatol Res 2009:39:366-373.

29. Doege $H$, Grimm D, Falcon A, Tsang B, Storm TA, Xu H, et al. Silencing of hepatic fatty acid transporter protein 5 in vivo reverses dietinduced non-alcoholic fatty liver disease and improves hyperglycemia. J Bio Chem 2008;283:22186-22192.

30. Lambert JE, Ramos-Roman MA, Browning JD, Parks EJ. Increased de novo lipogenesis is a distinct characteristic of individuals with nonalcoholic fatty liver disease. Gasteroenterology 2014;146:726-735.

31. Pettinelli P, Obregón AM, Videla LA. Molecular mechanisms of steatosis in nonalcoholic fatty liver disease. Nutr Hosp 2011;26:441-450.

32. Serviddio G, Giudetti AM, Bellanti F, Priore P, Rollo T, Tamborra R, et al. Oxidation of hepatic carnitine palmitoyl transferase-I (CPT-I) impairs fatty acid beta-oxidation in rats fed a methionine-choline deficient diet. PloS One 2011;6:e24084.

33. Begriche K, Massart J, Robin MA, Bonnet F, Fromenty B. Mitochondrial adaptations and dysfunctions in nonalcoholic fatty liver disease. Hepatology 2013;58:1497-1507.

34. Sunny NE, Parks EJ, Browning JD, Burgess SC. Excessive hepatic mitochondrial TCA cycle and gluconeogenesis in humans with nonalcoholic fatty liver disease. Cell Metab 2011;14:804-810.

35. Zhang W, Patil S, Chauhan B, Guo S, Powell DR, Le J, et al. Fox01 regulates multiple metabolic pathways in the liver: effects on gluconeogenic, glycolytic, and lipogenic gene expression. J Biol Chem 2006;281:10105-10117.

36. Salamone F, Galvano F, Cappello F, Mangiameli A, Barbagallo I, Li Volti $G$. Silibinin modulates lipid homeostasis and inhibits nuclear factor kappa B activation in experimental nonalcoholic steatohepatitis. Transl Res 2012;159:477-486. 